\title{
Design and Application of a New Splitter Plate Pressure Probe for Wind Tunnel Flow Measurements
}

\author{
Kasim Biber \\ Department of Mechanical Engineering, Faculty of Engineering, Architecture and Design, Bartin University, Bartin 74100, Turkey
}

\begin{abstract}
A new siplitter plate presure probe was developed for flow field measurements on an airfoil with slotted flap in a low speed wind tunnel with 7 by $10 \mathrm{ft}$ test section. Wind tunnel tests were conducted at a Reynolds number of 2.2 million and Mach number of 0.13 . The splitter plate was made of aluminum and had pressure taps on its one side. The probe can make many measurements in the plane of the plate simultaneously by using these pressure tabs. It was supported by a traversing strut in the wind tunnel and surveyed the flow field on the airfoil upper surface. Measured pressures were presented by isobars of coefficients. These isobars were connected with the pressure coefficients distributed over the airfoil. Results of splitter plate pressure probe compare well with other single-point measuring probes. However, results show that no matter how small the probe, its presence in the flow causes a disturbance, especially in the highly time-dependent separated flow regions.
\end{abstract}

Key words: Splitter plate-pressure probe, flow field pressures, wind tunnel instrumentation, flow field isobars, multi-element airfoils.

\section{Introduction}

Pressure measurements in wind tunnels are of interest not only for determining the pressure distribution on test models but also for determining flow field pressures in the wind tunnel test section. Flow field pressures are commonly measured at a single point and this measurement is repeated until all point measurements at prescribed locations are completed. This kind of point measurement may provide qualitative data when the flow is attached over the test model, but it may not be adequate when the flow is separated from the model surface.

The wind tunnel investigation reported by Biber [1] involved measuring such pressures in separated flows over an airfoil with a slotted flap. One objective from these tests was to provide flow field pressure data to validate computational codes developed on multi-element airfoils. The vast majority of wind tunnel tests on multi-element airfoils had been conducted for the measurements of velocity and

Corresponding author: Kasim Biber, Ph.D., associate professor, research fields: fluid mechanics/aerodynamics and energy. turbulence quantities as in Ref [2]. However, computational codes such as the one reported by Stevens [3], required flow field static pressures for their evaluation. Such pressure data were reported by Adair and Clifton [4], Nakayama and Kreplin [5] and Wentz and Ostawari [6], but they measured these pressures at single points and did not include separated flow at stall conditions. Therefore, there was a need to provide a new method of measuring pressures for validating computational codes developed for separated flows over airfoils, as in Ref [7].

Separated flow over airfoils may however involve both forward and reverse flow. Its static pressures can be measured at a single point, but this type of measurement is not capable of capturing the time dependent features of separated flow. Therefore, for measuring static pressures in separated flows, a new pressure measuring instrument called splitter plate-pressure probe was developed as part of wind tunnel test program reported by Biber [1], Biber and Zumwalt [8] and Biber and Zumwalt [9]. The splitter plate can make many measurements simultaneously 
and it can capture time averaged-static pressures for separated flow. The present paper first describes the experimental arrangement including design features of the new pressure instrument and then provides its example pressure data as obtained in the wind tunnel.

\section{Experimental Apparatus}

The tests were conducted in the Wichita State University (WSU) $2.13 \mathrm{~m} \times 3.05 \mathrm{~m}(7 \mathrm{ft} \times 10 \mathrm{ft}$ ) wind tunnel fitted with two inserts, providing a $2.13 \mathrm{~m}(7 \mathrm{ft})$

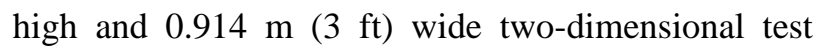
section. The test model used was $13 \%$ thick GA(W)-2 airfoil with $25 \%$ single-slotted flap. It had a reference

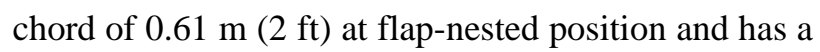
cove region where the flap retracts for the single-element case. Details of tunnel, model, supporting end plates and surface pressure taps are given by Biber and Zumwalt [9] and Wentz and Ostawari [6]. Flap positioning was based on previous wind tunnel tests of $\mathrm{GA}(\mathrm{W})-2$ airfoil at WSU, as reported by Biber [1]. The selected flap had a deflection of $30 \mathrm{deg}$ from chord line and 3\% chord gap without any overlap with the main wing element.

Wind tunnel tests were conducted at a Reynolds number based on the reference chord of 2.2 million, Mach number of 0.13 and an indicated dynamic pressure of $1,150 \mathrm{~N} / \mathrm{m}^{2}$ (24 psf). The transition on the main wing was fixed by $2.4 \mathrm{~mm}$ wide trip strips at $5 \%$ chord upper surface and $10 \%$ chord lower surface. The test section turbulence level was $1 \%$, as obtained by a single hot-wire probe.

The flow field two-dimensionality in the test section was evaluated by the visualization of separation patterns on the model upper surface. Tempera and kerosene flow showed a change in the two-dimensional flow character near the side walls with the airfoil stalled. Beyond the stall, a span-wise surface flow component within the separated zone appeared and extended toward the juncture of the model and sidewall, where a vortex pair was formed and sheds at the model trailing edge. However, this was limited to the outer $25 \%$ of the span. No boundary layer control was employed to reduce the effects of three-dimensional flow patterns.

The sidewall boundary layer did not have significant effect on the airfoil stall characteristics. This was probably due to the relatively short upstream length of the sidewalls, $1.06 \mathrm{~m}$ from the model leading edge. Besides tempera and kerosene, tufts were attached to the model upper surface to supplement the preceding results and particularly to observe the probe interference with the surface flow. The tufts did not show span-wise flow at pre-stall angles of attack, but at post stall angles, it was not clear if the sideway flapping of tufts was due to three-dimensional feature of separated flows or the probe interference.

\section{Development of Splitter Plate Pressure Probe}

The new instrument, called splitter plate-pressure probe, was specially designed and built for mapping the flow field static pressures over the airfoil. Fig. 1 shows geometric details of the new pressure probe. The idea for this instrument originated from the difficulty of measuring static pressures in the separated wake flows. The conventional pressure probes sense the pressure in the prescribed directions although the

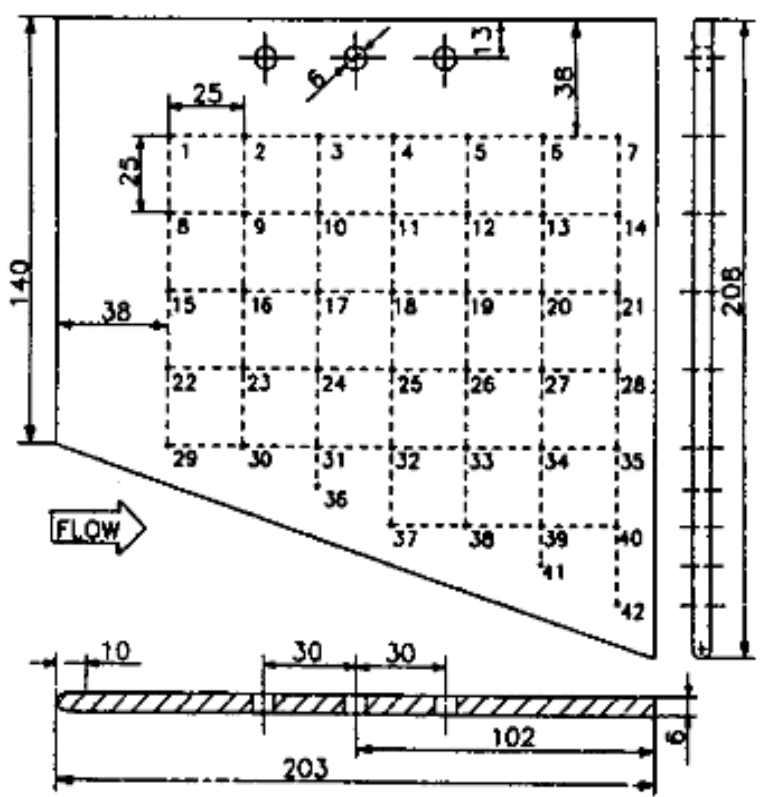


Fig. 1 Geometry of splitter plate-pressure probe with 42 pressure ports. All dimensions are in milimeters.

flow is multi-directional, especially, in the highly separated wakes. The splitter plate measures static pressures regardless of the flow direction in the plane of the plate, by pressure taps on its surface.

The splitter plate was mainly developed for measuring flow field pressures on airfoils. During its application, the major issue was the plate size and its support system. The wind tunnel blockage and three-dimensional effects, especially, at post-stall conditions were considered as major limitations. Tests showed that the plate would flutter to some degree at some high angle of attack.

The splitter plate was supported by a tunnel traversing strut, also used for other flow field surveys in the wind tunnel. The splitter plate can make many measurements simultaneously in the plane of the plate, by the pressure taps on the plate surface. It has an elliptic leading edge and rounded bottom edge for good surface flow quality. The slope of the bottom edge is straight rather than curved to get closer to the airfoil upper surface at all selected angles of attack. The plate was made of aluminum and had 42 pressure taps on its one-side. These taps were connected to stainless steel tubes buried inside the $6.35 \mathrm{~mm}$ thick plate. These tubes were extended vertically as much as $508 \mathrm{~mm}$ along the traversing strut and then linked to the tunnel pressure tranducers externally. The pressure transducers had a resolution of $\pm 2.4 \mathrm{~N} / \mathrm{m}^{2}$ (0.05 psf). The long tubing length would tend to smooth out any pressure fluctuations, so the pressure readings must be regarded as time-average values.

The flow quality on the plate surface was checked by the oil flow visualization with and without the two-dimensional inserts in the empty test section. The oil flow showed a small separation bubble at the leading edge, but the elliptic leading edge minimized the bubble size. Also, some vortices developed on the bottom edge due to its inclination with respect to the main flow. However, these flow features did not indicate a significant change in the pressure data obtained during the plate calibration.

The splitter plate surveyed the flow field at various survey stations above the airfoil model. Starting well above and downstream of the model, the survey was made by moving the plate in $127 \mathrm{~mm}$ horizontal (downstream) steps. This made the front two columns of pressure taps overlap the locations of the last two columns of the previous position. After moving downstream of the model, the plate was moved forward and lowered, at most $76 \mathrm{~mm}$. Downstream steps were made again. At least $6.35 \mathrm{~mm}$ clearance from the model surface was maintained. When sizable pressure differences were sensed at the same position by the plate overlap at two different steps, the data from the innermost taps on the plate were considered to be the most accurate. Otherwise, data from overlapped taps were averaged. Plate flutter limited the portion of the field that could be measured. It occurred at the most extended, that is, the lowest, strut position when in the wake of the model at high angle of attack. The flutter was monitored visually from the tunnel ceiling window and no data were taken when it was present.

A disk probe was also used to measure flow field static pressures at a single point. It is $38 \mathrm{~mm}$ diameter and $5 \mathrm{~mm}$ thickness with a pressure port on the center of each side. Its circumfarence was rounded to obtain a better flow quality on its surface. Before it was used, the probe was calibrated to make sure both sides of the probe read the same static pressures when aligned with the free-stream flow.

The accuracy of splitter plate pressure probe was checked against the disk probe. Both instruments surveyed the same statitions, but the disk probe picked data points closer to the model upper surface because of its relatively smaller size. The data obtained from these two instruments agreed reasonably well at the maximum lift conditions. There was however some discrepancy at post stall angles of attack. This appeared at the most downward probe positions where the splitter plate read higher pressures than the disk 
probe.

\section{Experimental Results}

The flow field static pressures on the upper surface of two-element airfoil were measured by the splitter plate pressure probe as described earlier. During the movement of the splitter plate, there was a gap in the pressure data from the airfoil upper surface. This gap was filled by the data obtained from the disk probe. Even though the data comparison between the splitter plate and disk probe did not show a significant difference, the disk probe was considered to yield better results close to the airfoil. This was due to the possiblity of interference between the relatively large size of splitter plate and the boundary layer on the airfoil surface.

Pressure data were presented by coefficient contours of constant pressures or isobars. These contours were connceted with the upper surface pressures in the airfoil bounded regions and they were left isolated in the far wake regions. They tend to approach to the airfoil a nearly orthogonal for the attached flows and parallel for the separated flows.

Figs. 2 and 3 show the test results for the two-element airfoil with 30 deg flap case. The airfoil stall occurred when the angle of attack reached 12.8 deg. For the stall angle of attack, Fig. 2 shows a gradual increase of contour values of pressures as moved downstream. While the most upstraem contour has a value of -2.5 , it becomes almost 0.0 at the wake of flap trailing edge. This means that the flow accelerated at the wing leading edge decelarates without any major steepness and reaches the free-stream pressure value in relatively short dowstream from the flap.

Notice the contour value of -1.5 on the flap leading edge. This indicates the regions of accelarating flow in the gap having relatively higher negative presurres, as expected. Also, the contours stay nearly orthogonal to the main wing because the flow is mainly attached. However, a small separated region is shown past the flap mid-chord. This is typical for the airfoil at stall angle of attack with 30 deg flap case.

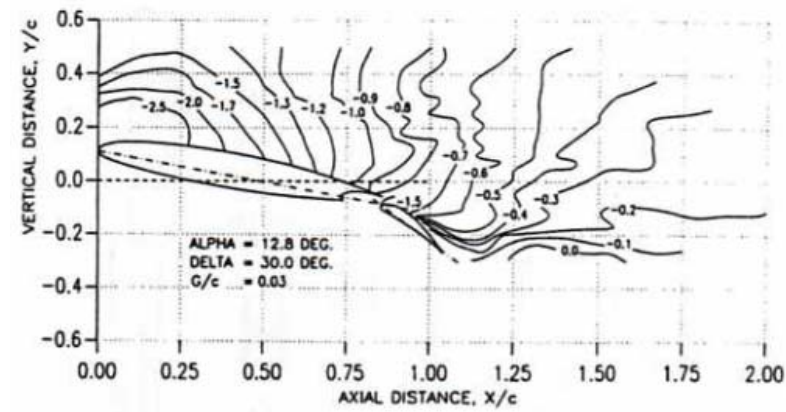

Fig. 2 Flow field static pressure coefficients contours for $12.8 \mathrm{deg}$, stall angle of attack case.

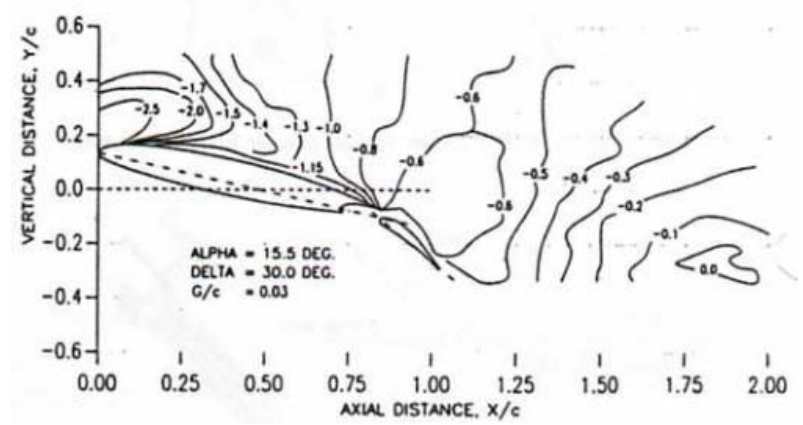

Fig. 3 Flow field static pressure coefficients contours for $15.5 \mathrm{deg}$, post-stall angle of attack case.

Splitter plate measurements were also presented for a representative angle of attack at post stall conditions. Fig. 3 shows the pressure contour values on airfoil upper surface at 15.5 deg angle of attack. As compared to the previous figure, there are clear changes in the flow field pressure distribution. While the contour value is -2.5 at the forward portion of wing, it becomes -0.5 after the wing trailing edge. For this case, there appears to be a region of constant pressure on flap upper surface, indicating a separated wake flow. Also, notice that there are contours staying nearly parallel on the main wing and flap upper surface. This means that the flow is separated on both wing and flap for the post-stall angle of attack. For this case, there is the contour value of 0.0 further downstream from the flap. This shows that the free-stream pressure is reached further downstream as the angle of attack past the stall.

\section{Conclusions}


A new siplitter plate presure probe was developed for a simultaneous measurement of flow field static pressures at 42 points. The new probe was employed for flow field measurements over a two-element airfoil in the Wichita State University 7 by $10 \mathrm{ft}$ low speed wind tunnel. Measured pressures were presented by isobars of coefficients. These isobars were connected with the pressure coefficients distributed over the airfoil. They were nearly orthogonal to the surface in the attached flow, and parallel to the surface in the separated regions. Free-stream pressure is reached at a further downstream location when the angle of attack is increaed to the post stall value. Results of splitter plate pressure probe compare well with other single-point measuring probes such as the disk probe. However, results show that no matter how small the probe, its presence in the flow causes a disturbance, especially in the highly time-dependent separated flow regions.

\section{References}

[1] Biber, K. 1991. "Experimental Studies of a Two-Element Airfoil with Large Separation.” Ph.D. thesis, Wichita State University.

[2] Braden, J. A., Whipkey, R. R., Jones, G. S., and Lilley, D. E. 1986. "Experimental Study of the Separating Confluent Boundary Layer.” NASA CR-3655, also AIAA paper 86-0505.

[3] Stevens, W. A., Goradia, S. H., and Braden, J. A. 1971. "Mathematical Model for Two-Dimensional Multi-component Airfoils in Viscous Flows.” NASA CR-1843.

[4] Nakayama, A., Kreplin, H. P., and Morgan, H. L. 1990. "Experimental Investigation of Flowfield about a Multi-element Airfoil.” AIAA Journal 28 (1): 14-21.

[5] Adair, D., and Clifton, W. 1988. "Turbulent Separated Flow in the Vicinity of a Single-Slotted Airfoil Flap.” Presented at the $26^{\text {th }}$ AIAA Aerospace Sciences Meeting, Reno, NV, Jan. 11-14, 1988.

[6] Wentz, W. H., and Jr Ostowari, C. 1983. “Additional Flow Field Studies of the GA(W)-1 Airfoil with 30-Percent Chord Fowler Flap Including Slot-Gap Variations and Cove Shape Modifications.” NASA-CR-3687, NAS 1.26:3687, AR-79-3.

[7] Zumwalt, G. W., and Elangovan, R. 1982. "Computation of Low Speed Flow Past Multi-element Airfoils with Large Flow Separation." In Proceedings of 13th ICAS Congress/AIAA Aircraft Systems and Technology Conference (Seeatle, WA), edited by B. Laschka, and R. Sraufenbiel, Vol. I, New York, 342-51.

[8] Biber, K., and Zumwalt, G. W. 1992. "An Experimental Study of a Two-Element Airfoil with Large Separation.” In Proceedings of 30th Aerospace Sciences Meeting and Exhibit, Reno, Nevada.

[9] Biber, K., and Zumwalt, G. 1993. "Flow Field Measurements of a Two-Element Airfoil with Large Separation.” AIAA Journal 31 (3): 459-64. 